\title{
Knowledge, Perception and Utilization of Postnatal Care of Mothers in Gondar Zuria District, Ethiopia: A Cross-Sectional Study
}

\author{
Fikirte Tesfahun • Walelegn Worku • \\ Fekadu Mazengiya - Manay Kifle
}

Published online: 26 April 2014

(c) The Author(s) 2014. This article is published with open access at Springerlink.com

\begin{abstract}
Mothers and their newborns are vulnerable to illnesses and deaths during the postnatal period. More than half a million women each year die of causes related to pregnancy and childbirth. The majority of deaths occur in less developed countries. Utilization of postnatal care (PNC) service in Ethiopia is low due to various factors. These problems problem significantly hold back the goal of decreasing maternal and child mortality. To assess mothers' knowledge, perception and utilization of PNC in the Gondar Zuria District, Ethiopia. Our study is a communitybased, cross-sectional study supported by a qualitative study conducted among 15-49 years mothers who gave birth during the last year. A multistage sampling technique was used to selected participants; structured questionnaires and focus group discussions were used to collect data. Data were entered into EPI info version 3.5.1 and exported into
\end{abstract}

F. Tesfahun

Yekokeb Berhan Program for Highly Vulnerable Children, Mahibere Hiwot Reproductive Health and Social Development Organazation, P. O. Box. No. 631, Gondar, Ethiopia

e-mail: seblefikir@yahoo.com

W. Worku · M. Kifle $(\square)$

Department of Environmental and Occupational Health and Safety, College of Medicine and Health Science, University of Gondar, P. O. Box. No. 196, Gondar, Ethiopia

e-mail: manay2000@gmail.com

W. Worku

e-mail: walelegnw@yahoo.com

F. Mazengiya

Department of Midwifery, College of Medicine and Health

Science, University of Gondar, P. O. Box. No. 196, Gondar, Ethiopia

e-mail: mazengiafek23@gmail.com
SPSS version 16.0 for the quantitative study and thematic framework analysis was applied to the qualitative portion. The majority of the women $(84.39 \%)$ were aware and considered PNC necessary (74.27\%); however, only $66.83 \%$ of women obtained PNC. The most frequent reasons for not obtaining PNC were lack of time (30.47 \%), long distance to a provider (19.25\%), lack of guardians for children care $(16.07 \%)$, and lack of service $(8.60 \%)$. Based on the multivariate analysis, place of residence (AOR 2.68; $95 \%$ CI 1.45-4.98), distance from a health institution (AOR 2.21; $95 \%$ CI 1.39-3.51), antenatal care visit (AOR 2.60; $95 \%$ CI 1.40-5.06), and having decisionmaking authority for utilization (AOR 1.86; $95 \%$ CI 1.30-2.65) were factors found to be significantly associated with PNC utilization. Mothers in the study area had a high level of awareness and perception about the necessity of PNC. Urban women and those who displayed higher levels of autonomy were more likely to use postnatal health services.

Keywords Knowledge of mothers ·

Mothers' perception - Utilization of postnatal care .

Lack of service - Ethiopia

$\begin{array}{ll}\text { Abbreviations } \\ \text { ANC } & \text { Antenatal care } \\ \text { AOR } & \text { Adjusted odd ration } \\ \text { CHWs } & \text { Community health workers } \\ \text { CI } & \text { Confidence interval } \\ \text { FGD } & \text { Focus group discussion } \\ \text { HEW } & \text { Health extension worker } \\ \text { IFPH } & \text { Integrated family health program } \\ \text { OR } & \text { Odd ratio } \\ \text { PNC } & \text { Postnatal care } \\ \text { SPSS } & \text { Statistical package for the social sciences }\end{array}$




\section{Background}

The health of mothers is mostly regarded as an indicator the health of the society. Globally, more than half a million women die each year from complications of pregnancy and childbirth [1-3]. A large proportion of maternal and neonatal deaths occur during the first $48 \mathrm{~h}$ after delivery. Thus, postnatal care (PNC) is important for both the mother and the child to treat complications arising from the delivery, as well as to provide the mother with important information [4]. Every year, four million infants die within their first month of life, representing nearly $40 \%$ of all deaths of children under age 5 year old. Almost all newborn deaths are in developing countries, with the highest number in South Asia and the highest rates in sub-Saharan Africa [5]. PNC coverage is low in Ethiopia; only $5 \%$ of mothers received PNC within the critical first 2 days after delivery [4]. Nationwide, $34.3 \%$ of mothers in Ethiopia receive PNC within the first 6 weeks after delivery. In the Amhara region (in which Gondar is found), the number of women attending PNC jumps to $44.5 \%$ [6]. It is an incontrovertible fact that PNC services help to safeguard women from complications following delivery and provide important opportunities to assess the infant's development. Moreover, PNC services help to offer newborn care (e.g. Counseling on breast feeding and Preventing Mother -to- Child Transmission) and other services like immunization and family planning which are crucial for both the mother and the infant [7-9].

In the course of a lifetime, an individual encounters the greatest risk of mortality during birth and the first 28 days of life (the neonatal period). The risk of maternal mortality and morbidity is also high at birth and in the immediate postnatal period. Each year, nearly 4 million newborns die during the neonatal period throughout the world. Three quarters of these deaths take place within 1 week of birth, 1-2 million die during the first day following birth, and most of these deaths occur at home [5]. The developing world has the highest prevalence of maternal and infant morbidity and mortality. A total of $99 \%$ of all maternal deaths occur in developing countries, where $85 \%$ of the world's population lives [10]. This is especially true in sub-Saharan African countries. Over 13,000 mothers, newborns, and children die every day in sub-Saharan Africa [11]. Ethiopia, one of the countries in sub-Saharan Africa, is among the six countries that contribute about $50 \%$ of the maternal deaths worldwide [12]. In 2005 in Ethiopia, the maternal mortality rate was found to be $673 / 100,000$. This rate has declined to 470 in 2008 as reported in 2010/11 [4, 13, 14].

The poor quality of post-natal care in Ethiopia is a result of weak health infrastructure, poorly trained health professionals, and inadequate supplies of drugs and equipment.
This, coupled with patients' poverty, results in low utilization of services. According to the 2005 Ethiopia Demographic and Health Survey, an estimated $95 \%$ of mothers nationwide did not receive PNC in the critical first 2 days after delivery [4]. Research indicates that maternal health care service utilization is affected by several factors including awareness of the health services, accessibility, socio-cultural beliefs, practices, individual attitudes, and health-care-seeking behaviors. However, the determinants of utilization of maternal health care services are not the same across different cultures and socioeconomic statuses within a society. There is little information about mothers' knowledge, perception, and utilization of PNC and factors that influence the use of PNC in the Gondar Zuria District of Ethiopia. This study aimed to elucidate the various factors influencing the use of these services within the district.

\section{Methods}

\section{Study Design and Study Setting}

The study was cross-sectional and community-based, using both quantitative and qualitative methods of data collection and analysis. The study was conducted from April to August 2011 in the Gondar Zuria District, which is among twenty-four districts in the North Gondar Administrative Zone in the Amhara Regional State, is located $700 \mathrm{~km}$ from Addis Ababa, Ethiopia. At the time of the study, the population of the district was 204,698, of which 101,009 were female. There are 3 urban and 35 rural wards, five health centers, and two heath posts working to maintain the health status of people in the district.

\section{Sampling Procedure}

The study population consisted of mothers from 15 to 49 years who gave birth in the last year in the selected wards and were residents of the district for at least 6 months. Multistage sampling technique was used to select study participants. The district was stratified into urban and rural wards, and then one urban and 12 rural wards were chosen by simple random sampling technique. In the study area, 12,282 women were estimated to be eligible (women who gave birth within the last year). The total sample size 836 was distributed proportionally to each strata: 131 urban and 705 rural households sampled were selected by systematic random sampling technique. If there was more than one mother within the same household, a lottery method was used to select the mother to be included.

Purposive sampling was used to select participants for focus group discussion (FGDs). Three FGDs which 
comprise a total of 6-8 individuals were conducted with mothers, health extension workers (HEWs), and community health workers (CHWs). A total of 16 mothers, three HEWs, and three CHWs participated in the FGDs.

\section{Data Collection Instrument}

The questionnaire was developed through review of related Ethiopian and international literatures. The questionnaire was prepared in English then translated into Amharic which is the local language of the area and back to English in order to ensure its consistency. The questionnaires consisted of information on socio-demographic characteristics, knowledge and perception of mothers towards PNC, and utilization of PNC services. Pre-testing of the questionnaire was done in other, unselected wards of the district and modifications were made based on the outcome of the pre-test. The data were collected by interview using a structured questionnaire. For the qualitative data, guiding questions for the FDGs were developed in English and converted to Amharic and then checked for validity. Camera and tape recorders were used in the discussion to record every discussion on the topics. Data were collected by 13 diploma nursing students after a 2 days training. Three supervisors and the principal investigators closely followed the day to day data collection process and ensured completeness and consistency of the collected questionnaires. Each questionnaire was checked for completeness and consistency by supervisors and principal investigators and incompletely filled questionnaires were discarded.

\section{Data Processing and Analysis}

The data were entered into EPI info version 3.5.1 and exported to SPSS version 16.0 for analysis. Descriptive statistics such as frequencies and percents were computed to describe the study population in relation to relevant variables. Bivariate and multivariate logistic regression analyses were employed. Those factors that were significant at the $20 \%$ level in the Bivariate logistic regression analysis were considered for the multivariate logistic regression analysis. Odds ratios with $95 \%$ Confidence Interval $(\mathrm{CI})$ and $p$ value of $<0.05$ were computed to assess the presence and degree of statistical association between dependent and independent variables. The qualitative data responses were coded, categorized, and then organized by content with thematic analysis.

\section{Ethical Considerations}

Ethical clearance for the study was obtained from the Institutional Review Board of University of Gondar. Official letters were written from Institute of Public Health to
North Gondar Health Office, to the District Health Office, and to each ward to get permission. Written and verbal consent was obtained from each participant after explaining the purpose and nature of the research. Participation in the study was on a voluntary basis and participants were informed their right to quit/refuse their participation at any stage of the study if they do not want to participate. Moreover, confidentiality of the information was assured by using an anonymous questionnaire.

\section{Result of the Study}

Socio-Demographic Characteristics of the Respondents

From the total 836 mothers $820(98.09 \%)$ completely filed and returned the questionnaire. The majority of mothers surveyed $(84.88 \%)$ were from rural areas, with the remainder $(15.12 \%)$ living in cities and towns. The mean age of study participants was 28.58 years, with a standard deviation of \pm 7.71 years. A large proportion of participants $(47.32 \%)$ travel a distance of one to $2 \mathrm{~h}$ on foot and $19.88 \%$ require more than $2 \mathrm{~h}$, whereas $32.80 \%$ of participants travel $<1 \mathrm{~h}$ to nearby health centers (Table 1 ).

\section{Awareness of Post Natal Care Service}

Six hundred ninety-two $(84.39 \%)$ of mothers were aware that they should receive PNC services after delivery. Those women who were aware of the need for PNC cited the following reasons for attending a clinic in the post-natal period: $97.69 \%$ of women mentioned the need to receive vaccinations; $42.49 \%$ to be counseled on family planning; $37.57 \%$ to prevent and treat delivery related problems; $22.98 \%$ to receive nutritional advice; $7.08 \%$ to discuss breastfeeding; $1.16 \%$ to receive advice on danger signs of pregnancy.

Among mothers who were aware that they should receive PNC services after delivery $85.84 \%$ were given information about PNC from HEWs, $17.77 \%$ from nurses, $8.24 \%$ from family, and $1.16 \%$ from doctors.

Maternal age, marital status, place of residence, previous visit by community health agents/HEWs, and having follow up for antenatal care had association with awareness of mothers about PNC service in both bivariate and multivariate logistic regression analysis $(p$ value $<0.05)$ (Table 2 ).

Mothers' Perception Towards Postnatal Care

The majority of mothers $(74.27 \%)$ stated that PNC is necessary for women and their children. Table 3 shows the factors that had an association with the positive perception to PNC. 
Table 1 Socio-demographic and economic characteristics of respondents, North Gondar, Ethiopia, 2011 ( $\mathrm{n}=820)$

\begin{tabular}{|c|c|c|}
\hline Characteristic & Frequency & Percent $(\%)$ \\
\hline \multicolumn{3}{|l|}{ Age (years) } \\
\hline $15-19$ & 109 & 13.29 \\
\hline $20-24$ & 178 & 21.71 \\
\hline $25-29$ & 173 & 21.10 \\
\hline $30-34$ & 181 & 22.07 \\
\hline$>35$ & 179 & 21.83 \\
\hline \multicolumn{3}{|l|}{ Marital status } \\
\hline Single & 34 & 4.15 \\
\hline Married & 706 & 86.10 \\
\hline Separated due to work & 27 & 3.29 \\
\hline Divorced & 33 & 4.02 \\
\hline Widowed & 20 & 2.44 \\
\hline \multicolumn{3}{|l|}{ Educational level } \\
\hline Illiterate & 677 & 82.56 \\
\hline Primary & 101 & 12.32 \\
\hline Secondary & 33 & 4.02 \\
\hline Diploma and above & 9 & 1.10 \\
\hline \multicolumn{3}{|c|}{ Husbands' educational level of $(n=753)$} \\
\hline Illiterate & 608 & 80.74 \\
\hline Primary & 87 & 11.55 \\
\hline Secondary & 37 & 4.91 \\
\hline Diploma and above & 31 & 4.12 \\
\hline \multicolumn{3}{|l|}{ Mothers' occupation } \\
\hline Housewife & 633 & 77.20 \\
\hline Farmer & 81 & 9.88 \\
\hline Private employ & 61 & 7.44 \\
\hline Government employ & 10 & 1.22 \\
\hline Daily labor worker & 33 & 4.02 \\
\hline Others & 2 & 0.24 \\
\hline \multicolumn{3}{|c|}{ Husbands' occupation $(\mathrm{n}=753)$} \\
\hline Farmer & 620 & 82.34 \\
\hline Private employ & 68 & 9.03 \\
\hline Government employ & 38 & 5.05 \\
\hline Daily labor worker & 25 & 3.32 \\
\hline Others & 2 & 0.27 \\
\hline \multicolumn{3}{|l|}{ Residence of participants } \\
\hline Urban & 124 & 15.12 \\
\hline Rural & 696 & 84.88 \\
\hline \multicolumn{3}{|c|}{ Distance from health institution (h) } \\
\hline$<1$ & 269 & 32.80 \\
\hline $1-2$ & 388 & 47.32 \\
\hline$>2$ & 163 & 19.88 \\
\hline
\end{tabular}

\section{Utilization of Post Natal Care}

Among mothers who give birth in the last 1 year, 548 $(66.83 \%)$ of them attended postnatal services. Above half
$496(60.49 \%)$ of the mothers attended for immunization of their babies, $175(21.34 \%)$ for family planning, 129 (15.73\%) for counseling on PNC, 29 (3.54 \%) for counseling on breastfeeding, and $15(1.83 \%)$ for physical examination (Fig. 1).

Two hundred seventy-two $(33.17 \%)$ mothers who didn't use PNC service provide different reasons for not attending PNC services. As depicted in (Fig. 2) majority of the mothers do not attend because of lack of time and the long distance required to travel in order to receive services.

Among mothers who utilize the service, $67.70 \%$ utilized once, $27.92 \%$ twice and $4.38 \%$ three and or more times within 6 weeks after delivery. Half of (52.19\%) mothers utilize services from HEWs and community health agents in outreach service, $46.90 \%$ of mothers from health institutions, and the other $0.91 \%$ of mothers receive PNC from trained birth attendants.

In a multivariate logistic regression analysis, the following factors were associated with the utilization of PNC: place of residence, distance from health institution, history of ANC, contact with community health agents within the last year, awareness about the need for PNC, history of institutional delivery, and the ability to make decisions regarding healthcare (Table 4).

\section{Results of the Focus Group Discussion}

Focus group discussions were conducted in the Chira Mantebro, Des Denzez, and Degoma wards in order to triangulate the quantitative data. The qualitative data responses of the FDGs were grouped into three themes: awareness about PNC, perception towards the care, and factors associated with the utilization of PNC.

\section{Awareness of Post Natal Care Service}

The majority of mothers demonstrated an awareness of immunization, family planning, and counseling on nutrition. Mothers reported that HEWs and community health agents informed them of the existence of PNC services. However, those who knew about the services did not have adequate information on when post-natal clinics are offered, or for whom. Most mothers assumed that the services were only given for children and vaccination 45 days after birth.

'...Community health workers inform us about the vaccination and child nutrition but we didn't practice because there is no full service here, the health facility is too far from here, and we do not have financial power...' (A 32 year-old mother, focused group discussion, Chira Mantebro ward). 
Table 2 Association of factors with awareness of mothers about postnatal care service, North Gondar, Ethiopia, 2011 $(\mathrm{n}=820)$
$1.00=$ Referent category,

* statistically associated $p$ value $<0.05$, ** statistically associated $p$ value $<0.001$

\begin{tabular}{|c|c|c|c|c|}
\hline \multirow[t]{2}{*}{ Variable } & \multicolumn{2}{|c|}{ Awareness of PNC } & \multirow{2}{*}{$\begin{array}{l}\text { Crude OR } \\
(95 \% \mathrm{CI})\end{array}$} & \multirow{2}{*}{$\begin{array}{l}\text { Adjusted OR } \\
(95 \% \mathrm{CI})\end{array}$} \\
\hline & Yes & No & & \\
\hline \multicolumn{5}{|l|}{ Age of participant (years) } \\
\hline $15-19$ & 77 & 32 & 1.00 & \\
\hline $20-24$ & 151 & 27 & $2.32(1.30-4.16)$ & $2.56(1.15-5.70)$ \\
\hline $25-29$ & 150 & 23 & $2.71(1.48-4.95)$ & $3.16(1.29-7.71)^{*}$ \\
\hline $30-34$ & 159 & 22 & $3.00(1.64-5.51)$ & $3.47(1.31-9.18)^{*}$ \\
\hline$>35$ & 155 & 24 & $2.69(1.48-4.87)^{*}$ & $2.93(1.17-7.33)^{*}$ \\
\hline \multicolumn{5}{|l|}{ Marital status } \\
\hline Single & 17 & 17 & 1.00 & \\
\hline Married & 616 & 90 & $6.84(3.37-13.89)^{* *}$ & $3.14(1.17-8.41)^{*}$ \\
\hline Separated due to work & 20 & 7 & $2.86(0.96-8.52)$ & $1.60(0.37-6.81)$ \\
\hline Divorced & 25 & 8 & $3.13(1.10-8.86)^{*}$ & $3.03(0.77-11.98)$ \\
\hline Widowed & 14 & 6 & $2.33(0.73-7.51)$ & $2.41(0.52-11.13)$ \\
\hline \multicolumn{5}{|l|}{ Place of residence } \\
\hline Rural & 573 & 123 & 1.00 & \\
\hline Urban & 119 & 5 & $5.11(2.05-12.77)^{* *}$ & $6.58(2.09-20.75)^{*}$ \\
\hline \multicolumn{5}{|c|}{ Distance from health institution (h) } \\
\hline$<1$ & 273 & 32 & $2.18(1.29-3.66)$ & $0.55(0.27-1.12)$ \\
\hline $1-2$ & 329 & 59 & $1.64(1.03-2.59)^{*}$ & $0.73(0.40-1.34)$ \\
\hline$>2$ & 126 & 37 & 1.00 & \\
\hline \multicolumn{5}{|c|}{ Number of children born alive } \\
\hline None & 41 & 18 & 1.00 & \\
\hline $1-5$ & 372 & 65 & $2.51(1.36-4.64)^{* *}$ & $0.40(0.16-1.01)$ \\
\hline$>5$ & 279 & 45 & $2.72(1.44-5.15)^{* *}$ & $0.29(0.09-0.85)$ \\
\hline \multicolumn{5}{|l|}{ ANC visit } \\
\hline Not used & 48 & 47 & 1.00 & \\
\hline Once & 143 & 39 & $5.12(3.07-8.55)^{* *}$ & $2.82(1.54-5.17)^{* *}$ \\
\hline Twice & 321 & 12 & $37.34(18.82-74.08) * *$ & $26.50(12.36-56.82)^{* *}$ \\
\hline Three and more & 180 & 10 & $25.03(12.03-52.42)^{* *}$ & $15.40(6.76-35.08)^{* *}$ \\
\hline \multicolumn{5}{|c|}{ Last 1 year visit health facility } \\
\hline Yes & 613 & 80 & $4.66(3.04-8.55)^{* *}$ & $1.44(0.82-2.63)$ \\
\hline No & 79 & 48 & 1.00 & \\
\hline \multicolumn{5}{|l|}{ Visit by HEW } \\
\hline Yes & 18 & 77 & $4.08(2.76-6.03)^{* *}$ & $2.01(1.19-3.39)^{* *}$ \\
\hline No & 505 & 51 & 1.00 & \\
\hline \multicolumn{5}{|c|}{ History of institutional delivery } \\
\hline Yes & 75 & 6 & $2.47(1.05-5.81)$ & $1.02(0.39-2.68)$ \\
\hline No & 617 & 122 & 1.00 & \\
\hline
\end{tabular}

the service...' (A community health worker, focused group discussion).

Mothers' Perceptions Toward PNC

Most participants in the discussions had a positive perception toward PNC and they encourage others to use PNC.

'... Health extension workers gave a drop to my child 15 days after I deliver at home and it helps to my 
Table 3 Association of factors with perception of mothers towards postnatal care service, North Gondar, Ethiopia, 2011 $(\mathrm{n}=820)$

$1.00=$ Referent category,

* statistically associated $p$ value $<0.05$, ** statistically associated $p$ value $<0.001$

\begin{tabular}{|c|c|c|c|}
\hline \multirow[t]{2}{*}{ Variable } & Perceive positively & \multirow[t]{2}{*}{$\begin{array}{l}\text { Crude OR } \\
(95 \% \text { CI })\end{array}$} & \multirow[t]{2}{*}{$\begin{array}{l}\text { Adjusted OR } \\
(95 \% \mathrm{CI})\end{array}$} \\
\hline & Yes & & \\
\hline
\end{tabular}

Age of participant(years)

$\begin{array}{lrlll}15-19 & 77 & 22 & 1.00 & \\ 20-24 & 151 & 27 & 2.54(1.42-4.55)^{*} & 1.87(0.98-3.55) \\ 25-29 & 150 & 23 & 1.19(0.71-2.04) & 0.69(0.38-1.27) \\ 30-34 & 159 & 22 & 1.39(0.82-2.38) & 0.97(0.54-1.76) \\ >35 & 155 & 24 & 0.79(0.48-1.33) & 0.59(.33-1.05)\end{array}$

Place of residence

$\begin{array}{lrrll}\text { Rural } & 487 & 209 & 1.00 & \\ \text { Urban } & 122 & 2 & 26.18(6.41-11.86)^{* *} & 11.22(2.53-49.80)^{* *}\end{array}$

Distance from health Institution

$\begin{array}{lrrll}<1 \mathrm{~h} & 240 & 29 & 2.60(1.54-4.41)^{*} & 0.93(0.50-1.71) \\ 1-2 \mathrm{~h} & 245 & 143 & 0.54(0.36-0.82) & 0.34(0.22-0.58) \\ >2 \mathrm{~h} & 124 & 39 & 1.00 & \end{array}$

ANC visit

Not used $\quad 59 \quad 56 \quad 1.00$

Once $\quad 156 \quad 26$

Twice $249 \quad 84$

There and more $145 \quad 45$

Visit by community health agent/HEW

\begin{tabular}{lrrll} 
Yes & 451 & 105 & $2.88(2.08-3.99)^{* *}$ & $1.95(1.33-2.86)^{* *}$ \\
No & 158 & 106 & 1.00 & \\
Awareness about PNC & & & & \\
Yes & 546 & 146 & $3.47(2.61-5.71)^{* *}$ & $3.55(2.11-5.97)^{* *}$ \\
No & 63 & 65 & 1.00 & \\
\hline
\end{tabular}

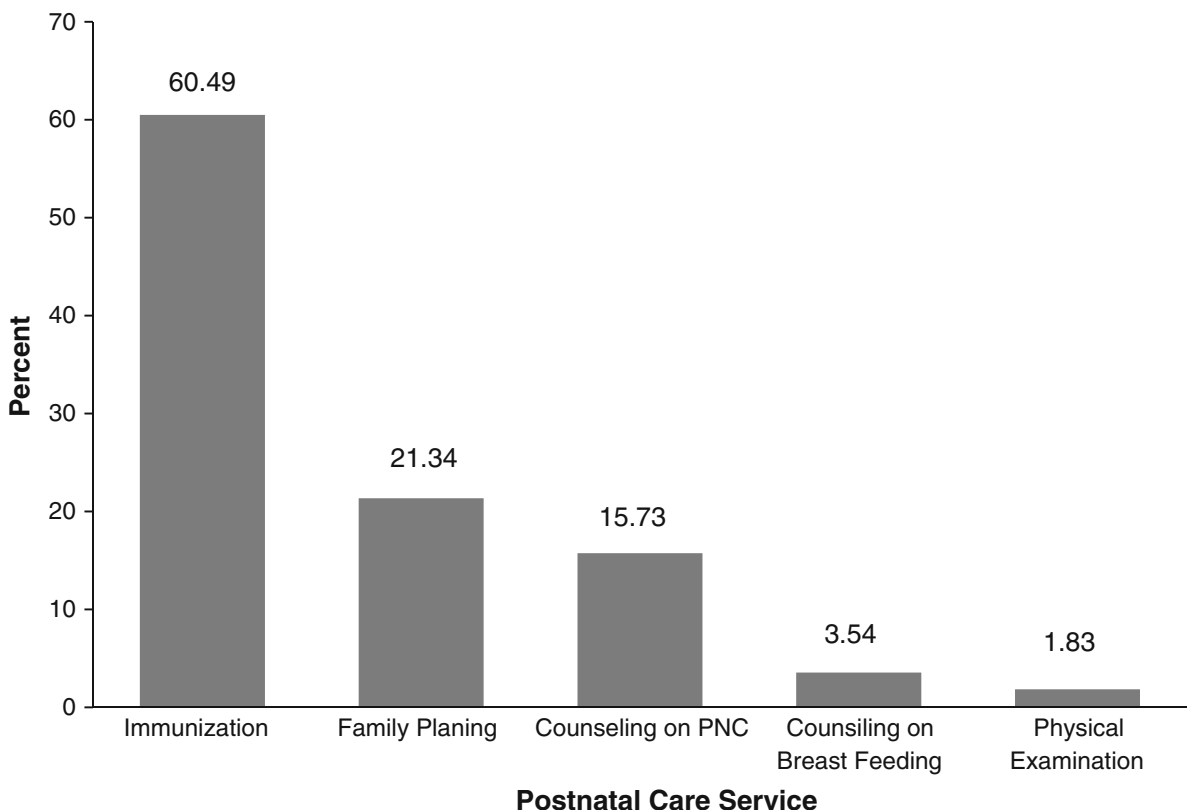

Fig. 1 Utilization of postnatal care by mothers who give birth in the last 1 year, North Gondar, Ethiopia, 2011

Postnatal Care Service
$3.04(1.61-5.74)^{*}$

$\begin{array}{ll}2.81(1.81-4.38)^{* *} & 1.34(0.74-2.41) \\ 3.06(1.86-5.02)^{* *} & 1.26(0.67-2.40)\end{array}$

$\begin{array}{ll}2.81(1.81-4.38)^{* *} & 1.34(0.74-2.41) \\ 3.06(1.86-5.02)^{* *} & 1.26(0.67-2.40)\end{array}$

$2.88(2.08-3.99)^{* *} \quad 1.95(1.33-2.86)^{* *}$

1.00

1.00 
Fig. 2 Mothers' reasons for not attending postnatal care service, North Gondar, Ethiopia, 2011

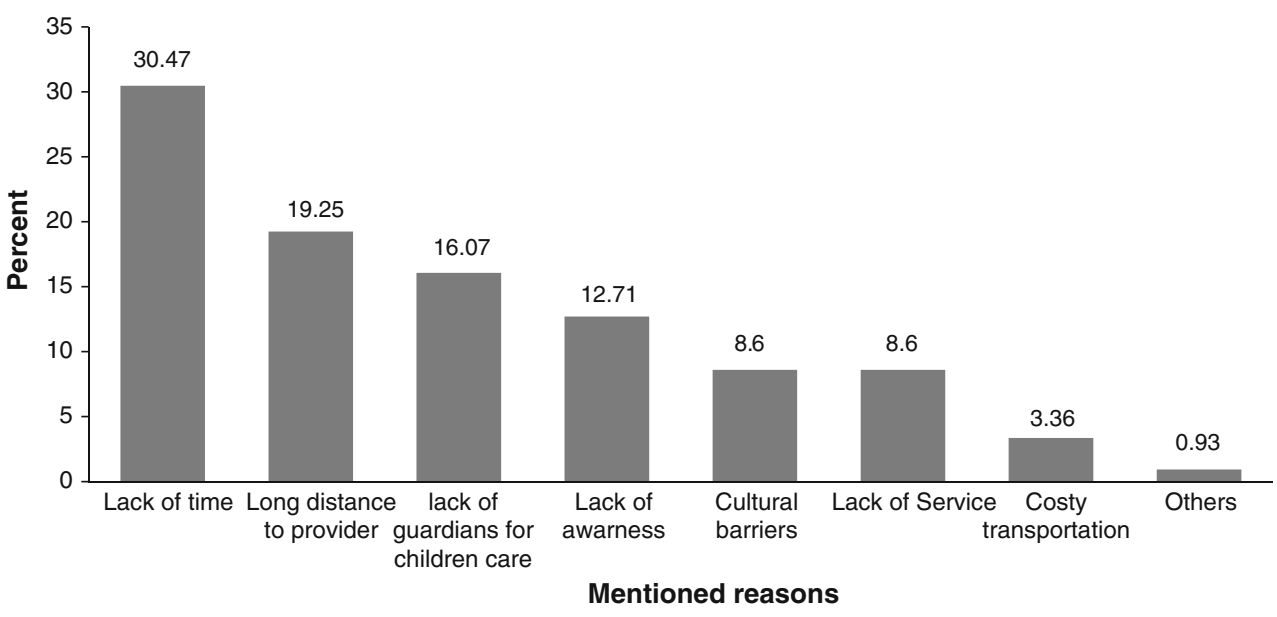

child. I went to the health post before 40 days for vaccination... it prevents my child form different diseases hence I want to have this service for my child to be healthy' (A 25 year-old mother, focused group discussion, Des Denzaz Ward).

In harmony with the mother, a HEA stated '...most mothers in this ward posses positive feelings towards PNC services yet remoteness of the area prevent some mothers not to have the service...'.

'... Some mothers need to use PNC and they are happy to go to the health post for the service...' (A community health worker)

Factors Associated with the Utilization of Postnatal Care

Distance from health organization was a major problem, especially in remote, rural wards, some participants complain that they needed to walk on foot for up to $2 \mathrm{~h}$ to reach the nearest health center.

'... A community health worker educate us about vaccination and how to care for our children but we fail to do because health post is too far and our husbands mostly did not allow us...' (A 24 year-old mother, focused group discussion, Degoma Ward).

Congruent evidence was also gathered from a health extension workers: '... there are village very far from here with no health extension workers so for such areas voluntary members of a society gave training and some services to mothers, but when we go for vaccination every month it is difficult to say they are getting the care ...'

Most women complained limited availability of health services (equipment and drugs): mainly in remote areas vaccines are less available. '... When my child gets sick there were no drug at the health post and full service even if they informed us about the care...' (A 20 year-old mother, focused group discussion, Des Degoma Ward). '... Only they vaccinate our children in our ward, there was no satisfactory service here and there was no drug ...' (A 26 year-old mother, focused group discussion, Des Denzaz Ward).

Another constraint mentioned by mothers was absent or frequent travel of HEAs out of the ward. '... I gave birth before three months but when I went there after a first month for vaccination the health worker were not available...' (A 32 year-old mother, focused group discussion, Chira Mantebro Ward).

Most mothers are responsible for house work such as baby care, preparation of food, and farming in rainy season which will delay their receiving of PNC services.

'... Community health worker told us about vaccination and counseled about nutrition but we have a work load to practice it...' (A 22 year-old mother, focused group discussion, Des Denzaz Ward).

Some participants did not feel the need for PNC services unless their children and they were sick after delivery. '...Since I did not get sick I did not go to the health post and never used family planning...' (A 27 year-old mother, focused group discussion, Degoma Ward).

\section{Discussion}

This community based study assessed knowledge, perception, and utilization of postpartum health care among women who give birth in the last year in Gondar Zuria District. The result showed that among the 820 postpartum women, 548 $(66.83 \%)$ obtained PNC during the 6 weeks following delivery. This is high compared with studies done in four other regions of Ethiopia (Amhara, Oromiya, Southern Nations, Nationalities and People's, and Tigray) (10\%) [15], Sidama zone (37.2 \%) [16], Uganda (58 \%) [7], Nepal 
Table 4 Association of factors with post natal care utilization, North Gondar, Ethiopia, 2011 $(\mathrm{n}=820)$
$1.00=$ Referent category,

$*$ statistically associated $p$ value $<0.05$, ** statistically associated $p$ value $<0.001$

\begin{tabular}{|c|c|c|c|}
\hline \multirow[t]{2}{*}{ Variable } & PNC utilization & \multirow[t]{2}{*}{ COR $(95 \% \mathrm{CI})$} & \multirow[t]{2}{*}{ AOR $(95 \% \mathrm{CI})$} \\
\hline & Yes & & \\
\hline
\end{tabular}

Age of participant

$\begin{array}{lrlll}15-19 & 70 & 39 & 1.00 & \\ 20-24 & 106 & 72 & 0.82(0.50-1.34) & 0.50(0.26-0.99) \\ 25-29 & 116 & 57 & 1.13(0.69-1.87) & 0.55(0.23-1.12) \\ 30-34 & 116 & 65 & 0.99(0.61-1.63) & 0.51(0.24-1.09) \\ >35 & 140 & 39 & 2.00(1.18-3.39)^{*} & 1.03(0.48-2.21)\end{array}$

Marital status

$\begin{array}{llll}\text { Single } & 17 & 17 & 1.00\end{array}$

Married $\quad 492 \quad 214$

Separated due to work $\quad 13 \quad 14$

$2.30(1.15-4.59)^{*}$

$1.50(0.62-3.63)$

$0.93(0.34-2.55)$

$0.79(0.24-2.58)$

Divorced

$0.83(0.32-2.18)$

$1.10(0.35-3.45)$

Windowed

$1.22(0.40-3.70)$

$1.22(0.33-4.48)$

Place of residence

$\begin{array}{llll}\text { Rural } & 449 & 247 & 1.00\end{array}$

Urban $\quad 99 \quad 25$

Distance from health institution (h)

$<1$

$1-2$

183

283

82

$>2$

105

81

Number of children born alive

$\begin{array}{lrr}\text { None } & 30 & 29 \\ 1-5 & 294 & 143 \\ >5 & 224 & 100\end{array}$

1.00

$2.18(1.37-3.47)^{* *}$

$2.68(1.45-4.98) * *$

$2.10(1.41-3.14)^{* *}$

$0.95(0.56-1.62)$

$2.66(1.82-3.89)^{* *}$

$2.21(1.39-3.51)^{* *}$

1.00

Know about maternal health service

Yes

279

No

269

97

175

29

43

1.00

$1.99(1.15-3.44)^{*}$

$2.11(0.97-4.59)$

$2.17(1.23-3.80)^{*}$

$1.83(0.77-4.35)$

ANC visit

Not used

Once

$41 \quad 74$

74

106

76

Twice

253

80

There and more

$148 \quad 42$

Know about PNC service

$\begin{array}{lll}\text { Yes } & 497 & 195\end{array}$

No

$\begin{array}{rr}497 & 195 \\ 51 & 77\end{array}$

$1.87(1.39-2.52)^{* *}$

$1.38(0.97-1.96)$

1.00

1.00

$2.52(1.55-4.08)^{* *}$

$1.36(0.76-2.45)$

$5.71(3.61-9.01)^{* *}$

$2.36(1.31-4.23) *$

$6.36(3.81-10.62)^{* *}$

$2.60(1.40-5.06)^{*}$

Visit by community health agent/HEW

$\begin{array}{lllll}\text { Yes } & 410 & 146 & 2.56(1.89-3.48)^{* *} & 2.66(1.39-5.06)^{* *} \\ \text { No } & 138 & 126 & 1.00 & \end{array}$

History of institutional delivery

$\begin{array}{ll}-77 & 4\end{array}$

$10.95(3.97-30.26)^{* *}$

$8.09(2.78-23.53)^{* *}$

No

$471 \quad 268$

Perception towards PNC

\begin{tabular}{lrrlr} 
Positive & 420 & 189 & $1.44(1.04-1.99)^{*}$ & $1.10(0.72-1.68)$ \\
Negative & 128 & 83 & & \\
Ability to make decisions for utilization & & & \\
Yes & 196 & 152 & $2.28(1.69-3.06)^{* *}$ & $1.86(1.31-2.65)^{* *}$ \\
No & 352 & 120 & 1.00 & \\
\hline
\end{tabular}


(34\%) [17], and Palestine (36.6\%) [18]. The difference may be attributed to time, place, and social context variation between the present study and previous studies.

In Ethiopia PNC coverage was $34.3 \%$ and, in the case of Amhara region $44.5 \%$, which is lower than from the present finding [6]. The variation could be due to socio-demographic characteristics, methodology difference, implementation of the service, and accessibility of health organizations.

The government of Ethiopia endorsed a strategy which is aimed at strengthening the health system to provide quality care, particularly skilled attendance at birth and emergency obstetrical care through a functional referral system that includes zonal hospitals and four health centers that refer to it as well as health posts [19]. Through the Health Extension Program, the government plans to extend primary healthcare to the rural poor through deployment of about 30,000 government-salaried HEAs, two per kebele. Kebele Councils with Woreda Councils recruit young, locally resident women who have completed grade 10 and speak the local language to become Health Extension Workers (HEWs). Two HEWs are posted at a health post for a population of approximately 5,000; they are to spend $75 \%$ of their time in outreach activities, teaching by example through three approaches: model families (40-60 families who are early adopters of desirable health practices), community organizations (e.g., Idir, Ekub, Mahber), and health post and outreach service delivery [20].

The majority $(84.39 \%)$ of mothers were aware that they were supposed to receive PNC services after delivery which is consistent with the studies done in Uganda (70.3\%) [7] and in Ethiopia [21]. Findings from the FGDs also showed that mothers had awareness and usually utilize the service 40 days after delivery. This high rate of awareness could be due to the range of government and non-government programs involved in the distribution of health information to the women such as the Integrated Family Health Program (IFPH) trained $\mathrm{CHW}$ s/agents for motivation of mothers to use maternal health services.

Postpartum maternal health care service awareness was associated with a previous visit by community health agents. Women who had antenatal follow up were 1.72 times more likely to be aware than women who did not have antenatal follow up. Similar studies in India show that mothers who attend antenatal care $(64.4 \%)$ were more aware than women who did not have $(33.3 \%)$ antenatal care [22]. It's also similar to studies conducted in Indonesia, Nepal and Uganda [7, 17, 23]. The possible explanation might be that mothers receive health education and counseling during community and antenatal visits.

The majority of mothers $(74.27 \%)$ perceived that PNC is helpful to mothers, and children's health, but only $66.83 \%$ of mothers utilize PNC services. Those mothers who had awareness about PNC, who were previously visited by community health agents, and who had antenatal follow-up have most likely considered the care as important for maintaining their health and for their child's health.

The most frequently cited reasons mentioned by the FGD participants for not utilizing PNC were believing that the treatments were not important unless mothers feel sick, negative experiences of women with the care, and considering the service accessible only for the child. Similar studies in Sweden show that women who had negative experiences were avoid PNC [24] other studies in Indonesia and the West Bank show that women in those areas have similar reasons to our study population for neglecting to utilize PNC [18, 23].

Place of residence, distance from a health organization, antenatal follow up, previous visit by community agents, and the ability to make a decision had effect on utilization of PNC service in this study. The participants in FGDs also raised these issues and stated that they affected the utilization of the service. Other studies on postpartum mothers revealed matching factors that have consequences for PNC utilization [17, 18, 22, 25-27].

In Bangladesh, urban mothers were more likely to receive PNC than rural mothers from both health professionals and non-health professionals [26]. Similarly, in this study, urban mothers were 2.68 times more likely to receive $\mathrm{PNC}$ than rural mothers (AOR 2. 68; $95 \% \mathrm{CI}$ 1.45-4.98). This might be due to the fact that urban women may have information from different sources on PNC or because of the availability of a good number of health institutions in urban areas.

Distance from the health institution remains a major problem as shown in previous literature; utilization of health services is strongly associated with access to health services [21, 23, 27-29]. In this study, one to $2 \mathrm{~h}$ travel to the nearby health centers resulted in women being 2.21 times more likely utilize the service than those who travel above $2 \mathrm{~h}$. Comparable evidence was also gathered from FDG participants. This may be inferred to the cost of travel in terms of time, money, or energy. Mothers $(71.91 \%$ ) who had antenatal care and mothers $(73.74 \%)$ who were previously visited by community health agents were more effective in utilizing PNC than those who had never been in any contact with the health system. This is in line with studies in Syria, Indonesia, Nepal, and Uganda [9, 18, 23, 30]. This could be due to the awareness of the mothers on possible postnatal complications as a result of previous contact with healthcare workers.

The ability to make a decision had a significant association with utilization of postpartum care. Mothers who can make a decision were more likely to use the service than those who cannot make a decision (AOR 1. 86; $95 \%$ CI 1.31-2.65). Studies indicate autonomy of decision making as a factor in the utilization of maternal health 
services [9, 29, 31]. The possible reason for mothers not to make a decision might be the community belief about the hierarchy of authority in the household and economic dependency of mothers on husbands. A contradictory result with the current research was identified in a study in Ethiopia [32]. This may be attributed to the prevalence of paternalism in the study area.

Many findings in the literature indicate a significant association of PNC utilization with the occupation of women, education of women, and the husbands' occupation [9, 17, 18, 33]. On the other hand, this study revealed no significant association with these variables. The majority of the respondents were illiterate, housewives and farmers which may be contributing to the lack of association in the study area.

\section{Conclusion}

The majority of the mothers had an awareness of PNC services but they did not know when they should seek those services. From the result it can be concluded that mothers' awareness about PNC service is more focused on the immunization component than others. Most mothers have a positive perception toward PNC services; however, mothers in a rural area possess a negative perception. PNC utilization was high but utilization of the most crucial elements was very low and large segments of mothers utilize only immunization services. Place of residence, distance from health institution, antenatal follow-up, previous visit by community health agents, and the ability to make decisions were significant factors that influence utilization of postnatal services.

Acknowledgments We would like to forward our deepest gratitude to Institute of Public Health, College of Medicine and Health Sciences, University of Gondar, for funding this thesis. We are also grateful for all academic staff of Institute of School of Public Health, College of Medicine and Health Sciences, University of Gondar for their contribution in one or another way in preparing this thesis work. Our heartfelt thanks go to study participants who spent their precious time in responding to the questionnaire.

Conflict of interest The authors declare that they have no conflict of interest.

Open Access This article is distributed under the terms of the Creative Commons Attribution License which permits any use, distribution, and reproduction in any medium, provided the original author(s) and the source are credited.

\section{References}

1. Abdella, A. (2010). Maternal mortality trend in Ethiopia. Ethiopian Journal of Health Development, 24(1), 115-212.
2. Ashford, L. (2002). Hidden suffering disabilities from pregnancy and child birth in less developed countries. www.unfpaorg/ mothers/disability.htm.

3. Starrs, A. M. (2006). Safe motherhood initiative: 20 years and counting. Lancet, 368(9542), 1130-1132.

4. Central Statistical Agency. (2006). Ethiopia demographic and health survey 2005. Addis baba, Ethiopia, p. 118-120

5. Lawn, J. E., Cousens, S., \& Zupan, J. (2005). 4 Million Neonatal Deaths: When? Where? Why? Lancet, 365(9462), 891-900.

6. Ministry of Health. Health and Health Related Indicators. Policy Plan Directorate Monitoring and Evaluation Case Team. Federal Democratic Republic of Ethiopia; Addis Ababa, Ethiopia 2008/9:12.

7. Nankwanga, A. (2004). Factors influencing utilisation of postnatal services in Mulago and Mengo Hospitals [master thesis], Kampala. Uganda: University of the Western Cape.

8. Warren, C., Mwangi, A., Oweya, E., Kamunya, R., \& Koskei, N. (2010). Safeguarding maternal and newborn health: Improving the quality of postnatal care in Kenya. International Journal for Quality in Health Care, 22(1), 24-30.

9. WHO. (1998). Safe motherhood: Postpartum care of the mother and newborn a practical guide. Geneva, p. 50-51.

10. WHO, UNICEF, World Bank. Maternal mortality in 2005. Geneva 2007 2008. http://www.whoint/reproductivehealth/pub lications/maternal_mortality_2005/index.html.

11. Friberg, I. K., Kinney, M. V., Lawn, J. E., Kerber, K. J., Odubanjo, M. O., Bergh, A.-M., et al. (2010). Sub-Saharan Africa's mothers, newborns, and children: How many lives could be saved with targeted health interventions? PLoS Medicine, 7(6), 1.

12. Afework, M. F. (2010). Achieving the maternal health millennium development goals in Ethiopia: Where are we and what needs to be done? Ethiopian Journal of Health Development, 24 Spec No 1, 87-88.

13. Ministry of Finance and Economic Development. (2010). MDGs report trend and prospects for meeting MDG by 2015. Ethiopia: Addis Ababa.

14. WHO. (2011). World health statistic (pp. 24-26). Geneva: World Health Organization.

15. Ali, M. K., Wuleta, B., Samuel, Y., Hibret, A., Mary, C., \& Yared, M. (2010). Programmatic correlates of maternal health care seeking behaviors in Ethiopia. Ethiopian Journal of Health Development, 24(Special Issue 1), 92-99.

16. Regassa, N. (2011). Antenatal and postnatal care service utilization in Southern Ethiopia: A population-based study. African Health Sciences, 11, 390-397.

17. Dhakal, S., Chapman, G. N., Simkhada, P. P., vanTeijlingen, E. R., Stephens, J., \& Raja, A. E. (2007). Utilisation of postnatal care among rural women in Nepal. BMC Pregnancy and Childbirth, 7(19), 1-9.

18. Dhaher, E., Mikolajczyk, R. T., Maxwell, A. E., \& Krämer, A. (2008). Factors associated with lack of postnatal care among Palestinian women: A cross-sectional study of three clinics in the West Bank. BMC Pregnancy and Childbirth, 8(26), 1-9.

19. Government of Ethiopia. (2007). Report on Progress in Implementing the World Fit for Children Plan of Action in Ethiopia. Addis Ababa

20. Addressing Community Maternal and Neonatal Health in Ethiopia. (2009). Report from National Scoping Exercise and National Workshop to Increase Demand, Accesses and Use of Community Maternal and Neonatal Health Services.

21. Warren, C. (2010). Care of the newborn: Community perceptions and health seeking behavior. Ethiopian Journal of Health Development, 24(1), 110-114.

22. Agarwal, P., Singh, M., \& Garg, S. (2007). Maternal health-care utilization among women in an urban slum in Delhi. Indian Journal of Community Medicine, 32, 203-205. 
23. Titaley, C. R., Hunter, C. L., Heywood, P., \& Dibley, M. J. (2010). Why don't some women attend antenatal and postnatal care services? A qualitative study of community members' perspectives in Garut, Sukabumi and Ciamis districts of West Java Province, Indonesia. BMC Pregnancy and Childbirth, 10(61), $1-12$.

24. Ladfors, L., Eriksson, M., Mattsson, L. -Å., Kyleback K., Magnusson, L., \& Milsom, I. (2001). A Population based study of swedish women's opinions about antenatal, delivery and postpartum care. Acta Obstetricia et Gynecologica Scandinavica, 80, 130-136.

25. Titaley, C. R., Dibley, M. J., \& Roberts, C. L. (2009). Factors Associated with non-utilisation of postnatal care services in Indonesia. Journal of Epidemiology and Community Health, 63(10), 827-831.

26. Rahman, K. M. M. (2009). Determinants of maternal health care utilization in Bangladesh. Research Journal of Applied Sciences, 4(3), 113-119.

27. Rahman, K. M. M. (2010). The determinants of use of postnatal care services for mothers: Does differential exists between urban and rural areas in Bangladesh? The Internet Journal of Epidemiology, 8(1), 1055.
28. Cham, M., Sundby, J., \& Vangen, S. (2005). Maternal mortality in the rural gambia, a qualitative study on access to emergency obstetric care. Reproductive Health, 2(3), 1-8.

29. Warren, C. (2010). Care Seeking for maternal health: Challenges remain for poor women. Ethiopian Journal of Health Development, 24(1), 100-104.

30. Bashour, H. N., Kharouf, M. H., Abdulsalam, A. A., El Asmar, K., Tabbaa, M. A., \& Cheikha, S. A. (2008). Effect of postnatal home visits on maternal/infant outcomes in Syria: A randomized controlled trial. Public Health Nursing, 25(2), 115-125.

31. Ethiopian Society of Population Studies. (2008). Maternal health care seeking behaviour in Ethiopia: Findings from EDHS 2005: In-depth Analysis of the Ethiopian Demographic and Health Survey 2005. 1-34.

32. Jemal, Y., \& Ayalew, M. (2011). Seid F (pp. 12-14). Maternal Health Beliefs: Attitudes and practices among Ethiopian Afar.

33. Babalola, S., \& Fatusi, A. (2009). Determinants of use of maternal health services in Nigeria-looking beyond individual and household factors. BMC Pregnancy and Childbirth, 9(43), $1-13$. 